\title{
Management of air flows inside steel silo during grain storage
}

\author{
I.A. Kechkin ${ }^{1, *}$, V.A. Ermolaev² , A.I. Romanenko ${ }^{3}$, V.V. Tarakanova ${ }^{3}$, and K.D. Buzetti ${ }^{3}$ \\ ${ }^{1}$ All-Russian Scientific and Research Institute for Grain and Products of its Processing - Branch of the V.M. Gorbatov Federal Research \\ Center for Food Systems of Russian Academy of Sciences, 109316 Moscow, Russia \\ ${ }^{2}$ Plekhanov Russian University of Economics, 117997 Moscow, Russia \\ ${ }^{3}$ K.G. Razumovsky Moscow State University of technologies and management (the First Cossack University), 109004 Moscow, Russia
}

\begin{abstract}
A study was conducted concerning effects of temperature and relative air humidity during longterm storage of wheat grain in a steel silo. The study was aimed at identifying the possibility of condensed moisture appearing under the silo roof. The probable periods of condensate in the space under the silo roof depending on the temperature difference inside and outside the silo have been determined. Some ways to prevent the condensate formation are proposed in the paper.
\end{abstract}

\section{Introduction}

A regular flat bottom steel silo intended for storing grain is provided with two installations impacting the air space inside the silo: active ventilation of the grain mass and over-grain space ventilation under the silo roof. Active ventilation affects the grain mass with upward flow of atmospheric air. This installation is used for cooling the grain to increase its shelf life [1], to prevent or eliminate self-heating in the grain mass. The second installation for ventilation the over-grain space is to remove condensate formed during the grain storage and settled on silo structures.

The maximum effect of active ventilation on the grain mass is achieved at the standard air volume not less than $10 \mathrm{~m}^{3} / \mathrm{ht} \mathrm{[2].} \mathrm{The} \mathrm{supply} \mathrm{of} \mathrm{the} \mathrm{required} \mathrm{air} \mathrm{volume}$ does not depend on the silo design and equipment or the stored grain crop; thus, we suggest ensuring this effect by changing the thickness of the grain layer. With a thinner layer thickness, a larger volume of air is supplied. We suggest controlling the grain mass thickness in the silo by the air pressure drop inside the grain mass. This method requires a differential pressure gauge to be installed outside the silo; its dial shall be marked so that to indicate the minimum air pressure drop for different grain crops.

When the ventilation is turned on; if the dial indicator hand is below the mark, then the grain mass in the silo should be reduced. The grain mass is being reduced until the dial indicator hand of the differential pressure gauge meets the corresponding mark on the dial [3]. At this state, the grain mass is being ventilated and supplied with the standard air volume.

After ventilating, the unloaded grain is returned into the silo. Air consumption is determined by the air pressure drop in the grain layer of a certain thickness. This method does not require consideration of possible air leaks between the ventilator and the grain mass, in contrast to the method determining the airflow rate at the ventilator. This method can be used to assess the tightness and efficiency of silo during operating process [4].

\section{Materials and method}

To study the reasons for the condensate formation and to develop methods for its elimination, real observations were performed of changes in the temperature and air humidity parameters in the upper part of two silos with a capacity of 2000 tons in the Tula Region and 10.000 tons in the Tambov Region during wheat storage. In the $2000 t$ silo (manufactured by RIELA, Germany), observations took 20 days (September-October) in 2016. The 10.000t silo (manufactured by GSCOR, USA) was observed for 4 months from October 2017 to February 2018. The values of temperature and relative air humidity were recorded simultaneously every 30 minutes in the following places: outside the silo, under the roof, on the grain surface and in the grain mass depth of the approximately $70 \mathrm{~mm}$ from the surface.

\section{Results}

It has been established that condensate forms in two variants of atmospheric air conditions and above the grain. The first variant: outside humidity $-100 \%$ (rainy weather), the air temperature above the grain and the outside the silo are approximately equal. Ventilation is not advisable.

The second variant: the outside temperature decreases sharply, but the temperature above the grain rises due to the heat release from the deep layers of the grain mass. Together with the heat, moisture is released from the grain, forming condensate in the over-grain space. In this case, there is a slow natural movement of

Corresponding author: kechkin87@ mail.ru 
air up through the grain mass due to the air pressure drop along the silo height [5].

Figure 1 shows graphs of temperature and air humidity parameters changes in a silo with a capacity of 2000 tons from September $20^{\text {th }}$ to October $10^{\text {th }}$. In the period from September $29^{\text {th }}$ to October $6^{\text {th }}$, there was an increase in temperature in the over-grain space under the silo roof from 10 to $20^{\circ} \mathrm{C}$ - curve 4 .

At the same time, the outside temperature decreased from 10 to $0{ }^{\circ} \mathrm{C}$ - curve 5 . In the over-grain space, moisture content increased from 7 to $12 \mathrm{~g} / \mathrm{m}^{3}$ and there were periods of condensate formation. During such a period, it is advisable to ventilate the space under the roof in order to reduce the moisture content in the air and prevent the condensate formation [6].

The following four figures show changes in temperature values (lower curve) and relative humidity (upper curve) in the upper part of the silo and outside. The silo was fully filled with wheat grain in mass of 10.000 tons [7].

Figure 2 shows the changes in air parameters inside the grain mass at a depth of $70 \mathrm{~mm}$ from the surface. The formation of condensate took place in early February. At the base of the observation period data, the relative air humidity practically did not change, its average value was about $70 \%$. The temperature varied from $12{ }^{\circ} \mathrm{C}$ at the beginning of observations to $-12{ }^{\circ} \mathrm{C}$ at the end of December. Changes in the values of relative air humidity and temperature were smooth and without significant fluctuations [8].

Figure 3 shows the changes in air parameters on the surface of the grain mass. The condensate formation was observed in late January - early February, with a 5-10day lead in the condensate formation in the grain layer at a depth of $70 \mathrm{~mm}$. Relative humidity varied from 55 to $100 \%$. The presented data indicate that the grain mass was moistened inside the silo, first the surface layer, and then in the upper layer at a depth of $70 \mathrm{~mm}$.

It can be assumed that moistening occurred as a result of condensate precipitation from the air of the over-grain space and accumulated condensate on the internal structures of the silo roof [9].

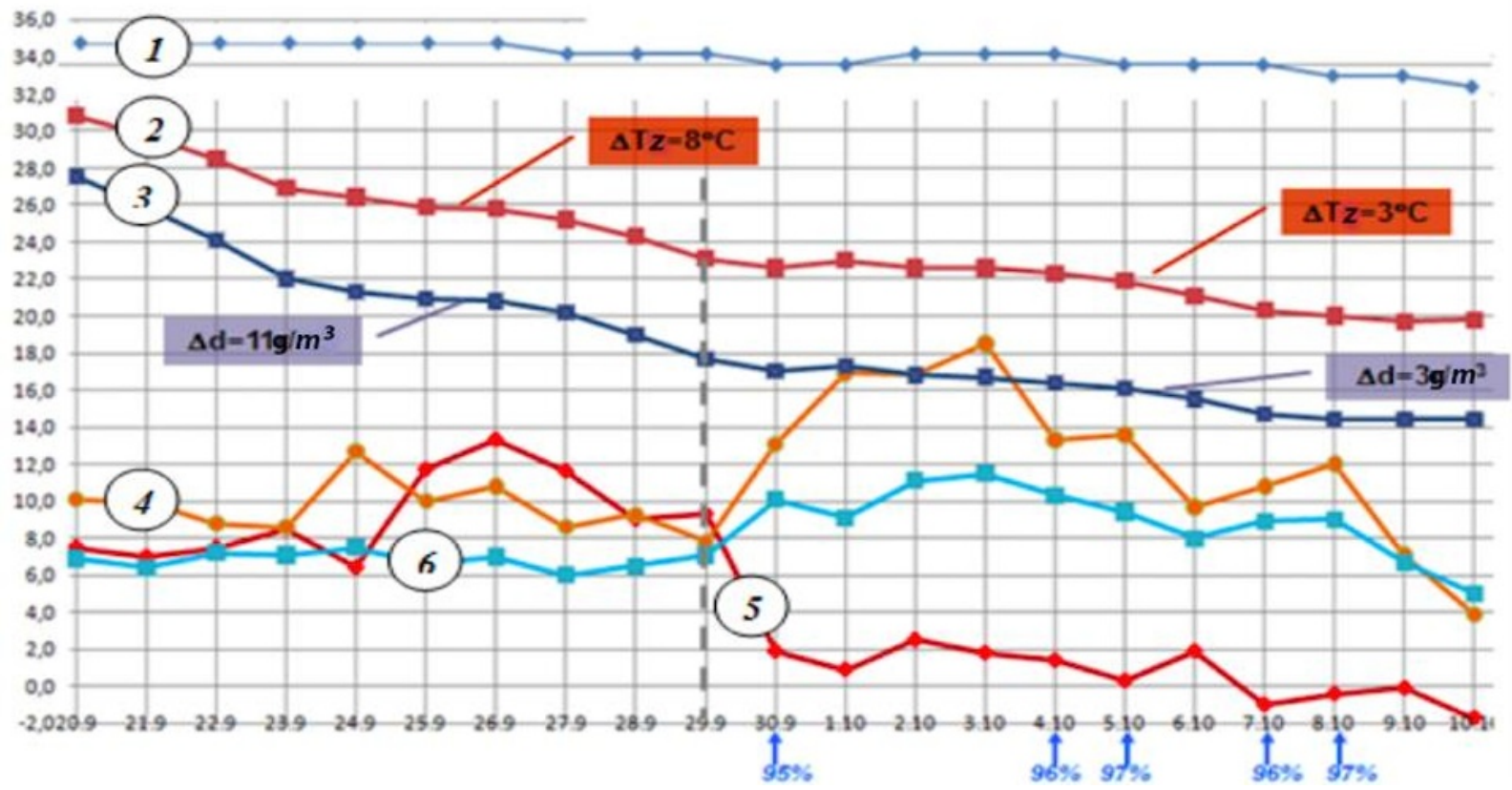

$\mathbf{1}$ - temperature at a $1 \mathrm{~m}$ depth from the surface of the grain mass; 2 - temperature in the surface layer of the grain mass, $70 \mathrm{~mm} ; \mathbf{3}$ air moisture content in the surface layer of the grain; 4 - air temperature above the grain, $600 \mathrm{~mm}$ from the surface; 5 - outside temperature; $\boldsymbol{6}$ - air moisture content above the grain.

Fig. 1. Average daily changes in air parameters inside and outside the silo with a capacity of 2000 tons of grain 


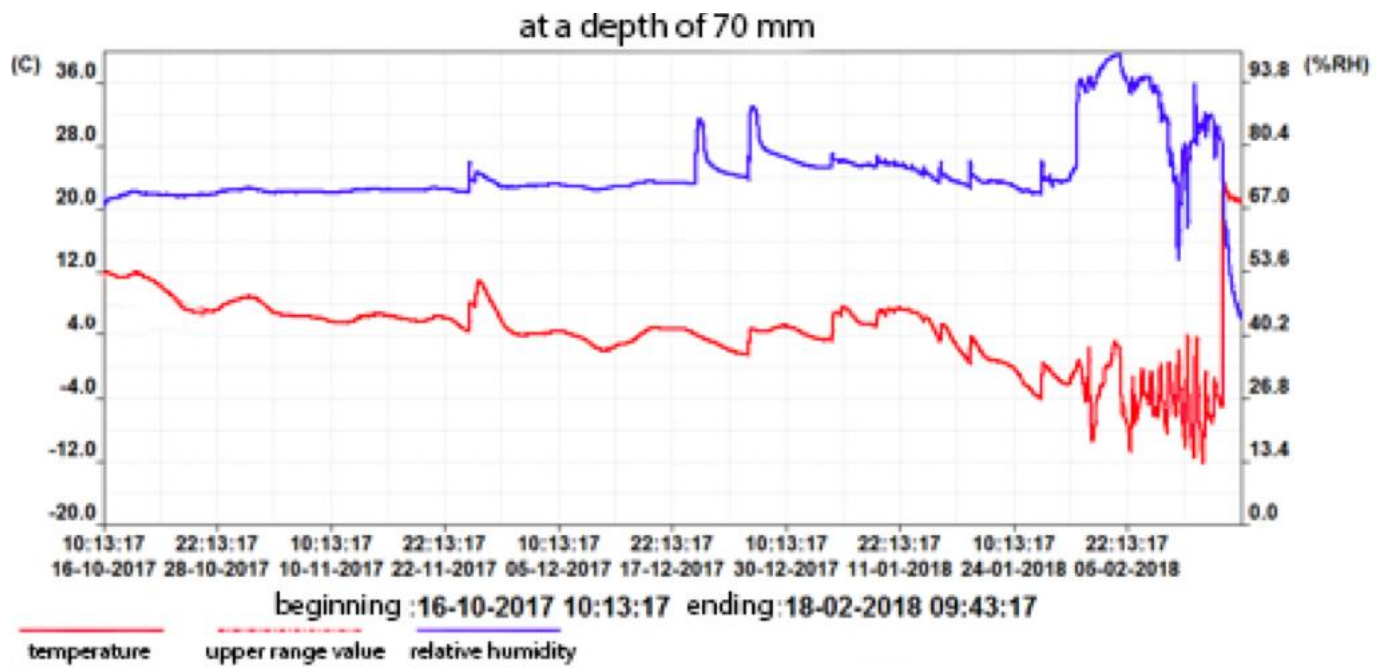

Fig. 2. Changes in relative humidity (upper curve) and temperature (lower curve) in the grain layer at a depth of $70 \mathrm{~mm}$ from the surface

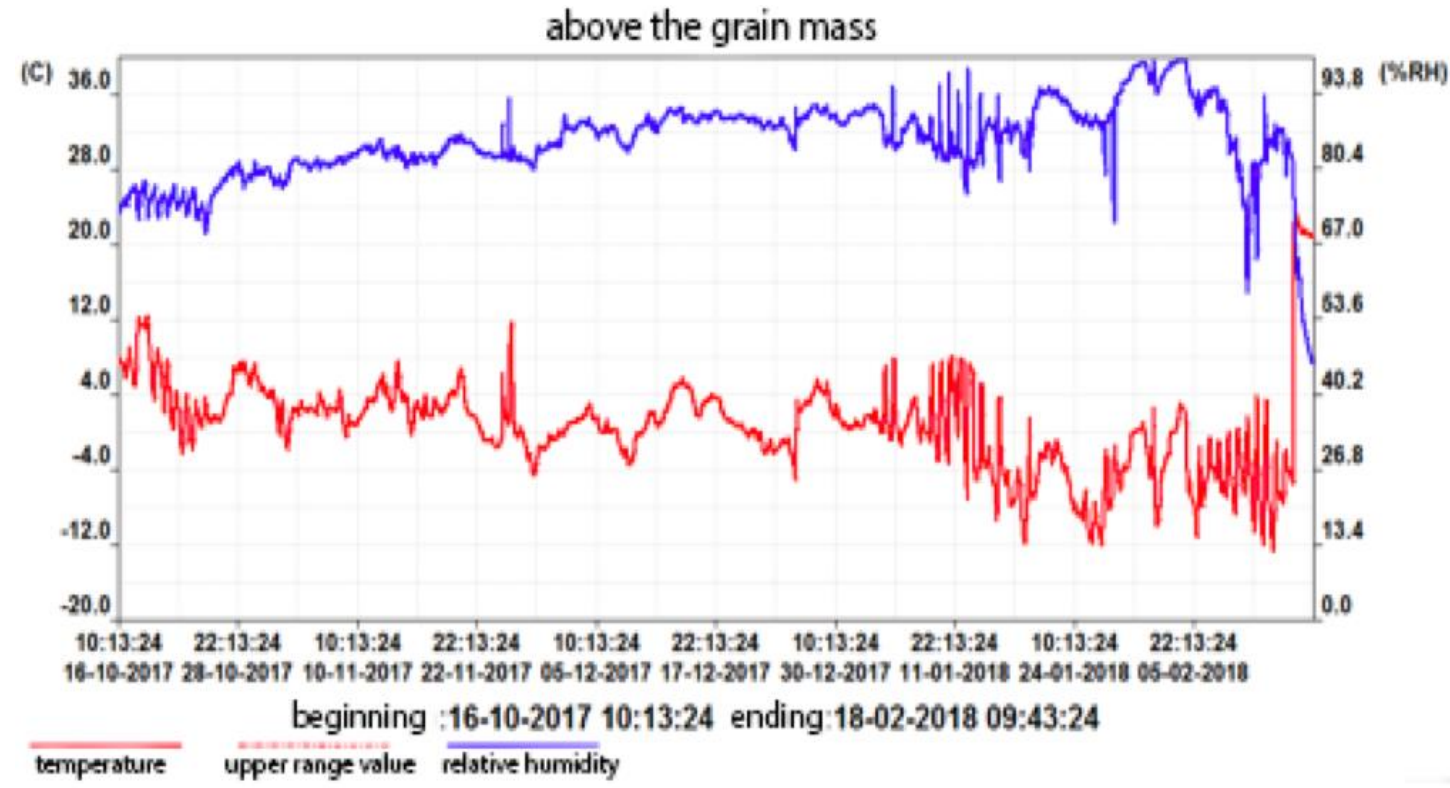

Fig. 3. Changes in relative humidity (upper curve) and temperature (lower curve) on the surface of the grain mass

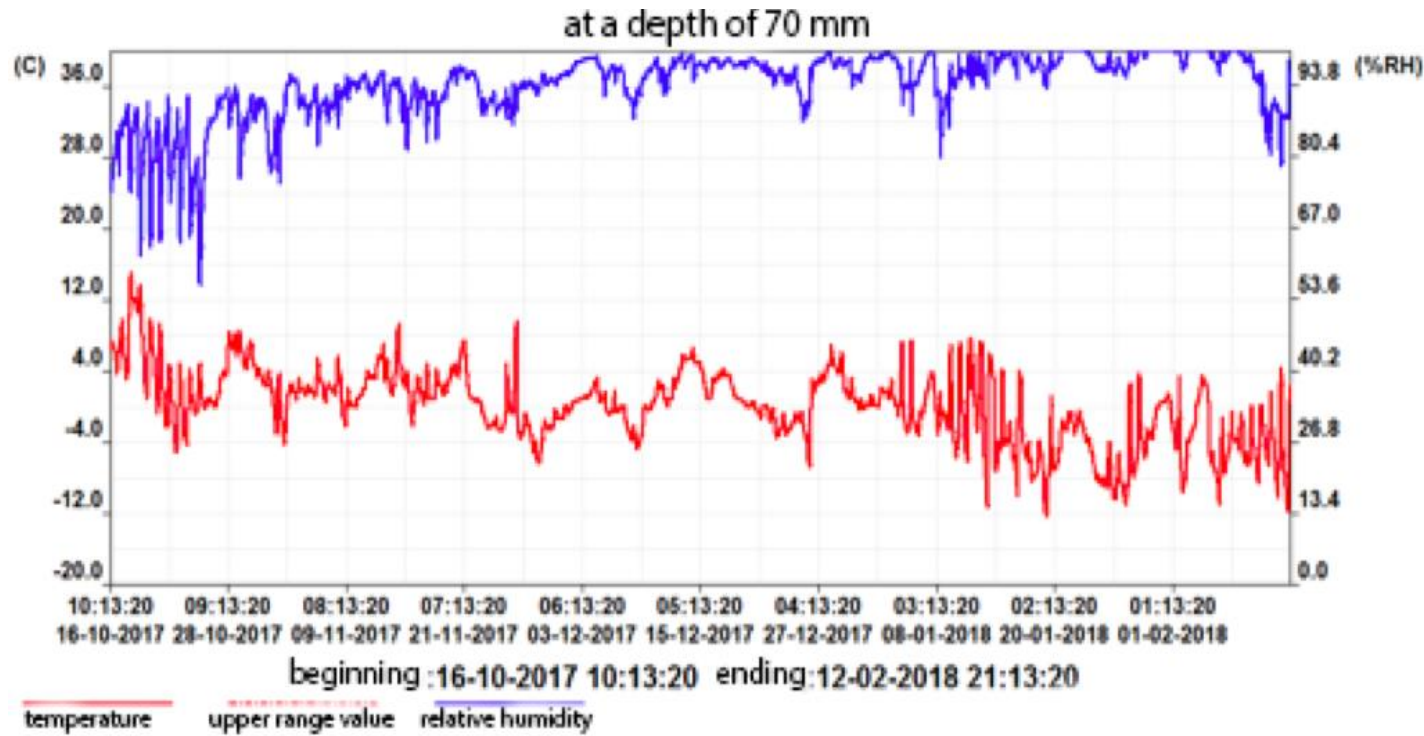

Fig. 4. Changes in the relative humidity (upper curve) and temperature (lower curve) above the grain mass under the silo roof. 


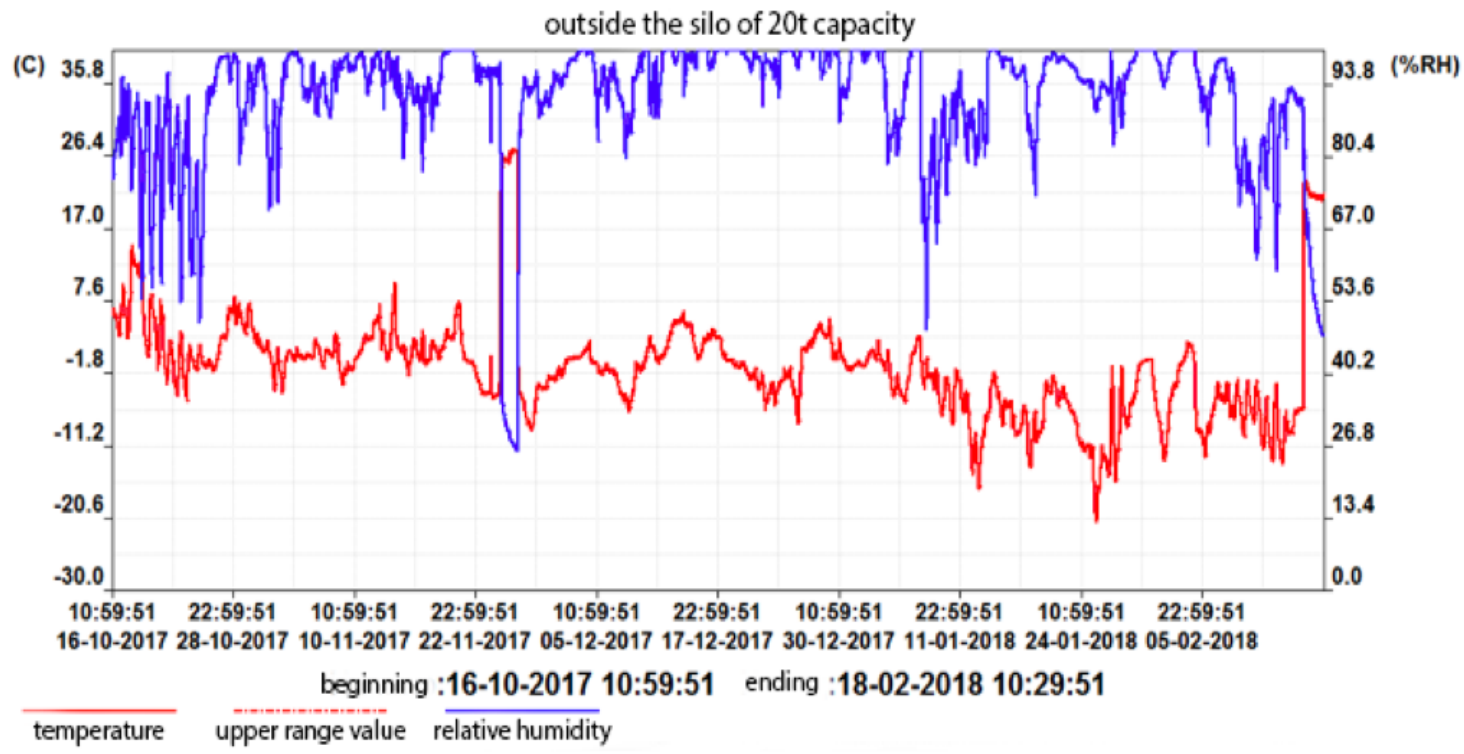

Fig. 5. Changes in relative humidity (upper curve) and temperature (lower curve) outside the silo

The temperature on the surface of the grain mass was changed in the same range as the temperature in the upper grain layer from 12 to $-12{ }^{\circ} \mathrm{C}$. During a short storage period, but at the same time with temperature changes, fluctuations in relative humidity were observed. The amplitude of the relative humidity fluctuations was within $20 \%$, and the temperature was within $16^{\circ} \mathrm{C}$.

The temperature in the over-grain space changed in the range from 15 to $-12{ }^{\circ} \mathrm{C}$ (Fig. 4), when the temperature outside changed from 15 to $-21^{\circ} \mathrm{C}$ (Fig. 5). The trends in over-grain space temperature changed corresponding to outside temperature changes and closely corresponding to temperature changes at the surface of the grain.

The periods of temperature fluctuations over the grain and its amplitude corresponded to the oscillations periods and the amplitude of temperature on the grain surface. Temperature fluctuations over and on the grain occurred with a greater frequency and amplitude comparing to the fluctuations in the outside temperature. This ratio of temperatures in the upper part of the silo and outside can be explained by the uneven heat released from the deep layers of the grain mass under the silo roof.

There were periods of over-grain temperature exceeding the outside temperature, and later the temperatures outside and under the silo roof leveled off. Such fluctuations in temperature occurred even during the day apparently due to the heat released from the deep layers of the grain mass being emitted in impulses. The relative humidity of the air followed the heat release [10].

The condensate formation in the over-grain space occurred in the $2^{\text {nd }}$ month of observation or the $3^{\mathrm{d}}$ month of storage after loading the silo. The total duration of high humidity (exceeding $98 \%$ ) in the over-grain space was about 600 hours. At a positive temperature and $100 \%$ humidity outside, the air temperature of the overgrain space was close to the outside ones, and the relative humidity was no more than $90 \%$. When the outside temperature was about $0{ }^{\circ} \mathrm{C}$ and lower and the humidity was $100 \%$, condensation occurred in the overgrain space. The air temperature inside and outside the silo were approximately equal, the differences amounted to $1-2{ }^{\circ} \mathrm{C}$.

There were periods when condensate in the over-grain space was formed with a drier air outside. This occurred at a positive temperature above the grain and a negative temperature outside. This state corresponded to periods of pulsed heat release from the depth of the grain mass. These periods of condensation are shown in the following table. In each period given in the table, the outside temperature varied within no more than $5{ }^{\circ} \mathrm{C}[11]$.

Condensate formed during periods of heat release is the greatest danger to grain preservation. If air humidity outside is $100 \%$ (rainy weather), the air in the overgrain space is cooled by no more than $1-2{ }^{\circ} \mathrm{C}$; when the heat is released from the grain, the air is cooled more than $10^{\circ} \mathrm{C}$, for example, on January $12^{\text {th }}$ from +7 to -5 ${ }^{\circ} \mathrm{C}$ (according to the table).

When it is cooled by $1-2{ }^{\circ} \mathrm{C}$, the temperature ranges from -15 to $+15{ }^{\circ} \mathrm{C}$, at the dew point the moisture content decreases by $0.1-0.6 \mathrm{~g} / \mathrm{m}^{3}$. This amount of moisture precipitates from the air. When it is cooled by $12{ }^{\circ} \mathrm{C}$ as in the above example, the moisture content decreases by $6 \mathrm{~g} / \mathrm{m}^{3}$. Much more moisture can be released from the air comparing to the amount of moisture released during rainy weather [12].

The time of condensate formation due to the release of heat from the grain mass was less than $15 \%$ of the total period of condensate formation in the silo in these studies. During these periods of condensate formation, the space under the silo roof should be ventilated in order to prevent formation of condensate and remove excess moisture from the internal volume of the granary.

Obtained observational data on changes in temperature and humidity parameters of air in a silo with a capacity of 10.000 tons confirm the results of studies in a silo with a capacity of 2.000 tons. 
Table 1. Temperature and humidity parameters of air in a silo with a capacity of 10,000 tons

\begin{tabular}{|c|c|c|c|c|c|c|c|c|c|c|c|}
\hline \multicolumn{5}{|c|}{$\begin{array}{l}\text { Period of condensate formation above } \\
\text { the grain at relative humidity } 89-100 \%\end{array}$} & \multicolumn{7}{|c|}{ Temperature-humidity air (average values) } \\
\hline \multicolumn{2}{|c|}{ Beginning } & \multicolumn{2}{|c|}{ Ending } & \multirow{2}{*}{$\begin{array}{l}\text { Total } \\
\text { time }\end{array}$} & \multirow{2}{*}{$\begin{array}{c}\text { Over grain } \\
\text { under the } \\
\text { silo roof } \\
\begin{array}{c}\text { Tempe- } \\
\text { rature }\end{array}\end{array}$} & \multicolumn{2}{|c|}{ Outside the silo } & \multicolumn{2}{|c|}{ On the grain surface } & \multicolumn{2}{|c|}{$\begin{array}{l}\text { In the upper grain layer } \\
\text { in the depth of } 70 \mathrm{~mm}\end{array}$} \\
\hline Date & Time & Date & Time & & & $\begin{array}{l}\text { Tempe- } \\
\text { rature }\end{array}$ & $\begin{array}{c}\mathrm{R}, \text { humidity, } \\
\%\end{array}$ & $\begin{array}{c}\text { Tempe- } \\
\text { rature }\end{array}$ & $\begin{array}{l}\text { R, humidity, } \\
\%\end{array}$ & $\begin{array}{l}\text { Tempe- } \\
\text { rature }\end{array}$ & $\begin{array}{l}\mathrm{R}, \text { humidity, } \\
\%\end{array}$ \\
\hline 10.1 & 9.00 & 10.1 & 11.00 & 2 & 1.6 & -3.3 & 88 & 2.9 & 93 & 7 & 77 \\
\hline 10.1 & 11.00 & 10.1 & 16.00 & 5 & 6.4 & -2.5 & 75 & 7.5 & 84 & 7 & 77 \\
\hline 11.1 & 8.00 & 11.1 & 9.00 & 1 & -2 & -6.7 & 89 & 2.6 & 95 & 7 & 77 \\
\hline 11.1 & 17.00 & 11.1 & 19.00 & 2 & 6.8 & -1.7 & 90 & 7.9 & 84 & 7.5 & 76 \\
\hline 12.1 & 10.00 & 12.1 & 12.00 & 2 & 4.5 & -5 & 87 & 7 & 85 & 7 & 76 \\
\hline 12.1 & 13.00 & 12.1 & 20.00 & 7 & 7 & -5 & 83 & 7.8 & 82 & 7 & 75 \\
\hline 13.1 & 8.00 & 13.1 & 22.00 & 14 & 5 & -12 & 80 & 6.8 & 82 & 7 & 75 \\
\hline 14.1 & 9.00 & 14.1 & 15.00 & 6 & -4.3 & -9 & 83 & -4 & 86 & 6 & 74 \\
\hline 14.1 & 15.00 & 14.1 & 21.00 & 6 & 4 & $-7,7$ & 84 & 5 & 83 & 6 & 74 \\
\hline 16.1 & 10.00 & 16.1 & 18.00 & 8 & 3.5 & -6 & 92 & 3.2 & 81 & 5 & 73 \\
\hline 25.1 & 20.00 & 25.1 & 4.00 & 8 & -9 & -20 & 89 & -10 & 88 & -2 & 71 \\
\hline 27.1 & 20.00 & 27.1 & 1.00 & 5 & -5 & -15 & 88 & -6 & 89 & 0.2 & 73 \\
\hline 1.2 & 17.00 & 1.2 & 18.00 & 1 & 2 & $-9,7$ & 95 & 2.2 & 99 & 1.7 & 95 \\
\hline 1.2 & 18.00 & 1.2 & 19.00 & 1 & -0.7 & $-10,3$ & 94 & $\begin{array}{l}-1.4 \\
\end{array}$ & 98 & -1.3 & 94 \\
\hline 12.2 & 20.00 & 12.2 & 21.00 & 1 & -1.6 & $-9,7$ & 86 & -6.8 & 81 & -6.5 & 80 \\
\hline
\end{tabular}

\section{Conclusion}

Based on the above date, the following conclusions can be made:

1. It was revealed that during the storage of grain in a metal silo, condensate forms on the surface of the grain mass, and subsequently in the depth of the upper layer (about $70 \mathrm{~mm}$ ), which reduces the resistance of grain during storage. To ensure the grain safety, it requires ventilation of the space above the grain and under the roof.

2. It has been established that condensate forms in two varieties of atmospheric conditions and over-grain air parameters. In the first variant, the outside air has $100 \%$ humidity (rainy weather), the air temperature above the grain and the outside are approximately equal.

3. In the second case, the temperature outside decreases, but the temperature above the grain increases due to the heat released from the deep layers of the grain mass. Along with the heat, moisture is released from the grain, forming condensate in the upper part of the silo. In this case, natural ventilation of the grain mass occurs at low air speeds due to the pressure drop over the silo height.

4. Ventilation of the over-grain space should be carried out during periods of condensate formation due to heat generation under the silo roof, when the air in the atmosphere is drier than the air inside the upper part of the silo. Ventilators should turn on automatically when a certain temperature difference is reached under the silo roof and outside.

\section{References}

1. V. Vassiliev, F. Magni, S. Chernishev, V. Kostege, Impact of the $3 d$ flow effects on the silo combustor thermal state in Proc. of the ASME Turbo Expo Cep. 881-890 (2012)

2. M.B. Toffolo, E. Boaretto, M.A.S. Martin, D.M. Master, Microarchaeology of a grain silo: insights into stratigraphy, chronology and food storage at late bronze age ashkelton, Israel J. of Archaeolog. Sci. 177-188 (2018)

3. M.R. Bonner, M.C.R. Alavanja, Pesticides, human health, and food security Food and Energy Security 6(3), 89-93 (2017)

4. W.J. Davies, J.M. Ribaut, Stress resilience in crop plants: Strategic thinking to address local food production problems Food and Energy Security 6(1), 12-18 (2017)

5. C. Pollock, Sustainable farming: Chasing a mirage? Food and Energy Security 5(4), 205-209 (2016)

6. B.H. Cervelin, D. Conti, M.A. Diniz-Ehrhardt, J.M. Martínez, A computer model for particle-like simulation in broiler houses Computers and Electron. in Agricult. 1-14, (2017)

7. M.J. Oates, A. Ruiz-Canales, M. Ferrández-Villena, A.F. López, A low cost sunlight analyser and data logger measuring radiation Computers and Electron. in Agricult. 38-48 (2017)

8. C. Gilmore, M. Asefi, J. LoVetri, J. Paliwal, Industrial scale electromagnetic grain bin monitoring Computers and Electron. in Agricult. 210-220 (2017)

9. P.J. García Nieto, E. García-Gonzalo, J. Bové, M. Duran-Ros, J. Puig-Bargués, Modeling pressure drop produced by different filtering media in microirrigation sand filters using the hybrid $A B C$ MARS-based approach, MLP neural network and M5 model tree Computers and Electron. in Agricult. 65-74 (2017) 
10. Y. Huang, C. Li, Real-time monitoring system for paddy environmental information based on DC powerline communication technology Computers and Electron. in Agricult. 51-62 (2017)

11. G.D. Stone, D. Glover, Disembedding grain: Golden Rice, the Green Revolution, and heirloom seeds in the Philippines Agricult. and Human Values 87-102 (2017)
12. M. Bhatta, V. Belamkar, P.S. Baenziger, A. Morgounov, Genome-wide association study reveals novel genomic regions for grain yield and yield-related traits in drought-stressed synthetic hexaploid wheat Int. J. of Molecular Sci. 19(10), (2018) 